\title{
APPLICATION OF INFORMATION ANALYSIS SYSTEM IN THE SPHERE OF HISTORICAL EDUCATION: ADVANTAGES AND PROBLEMS
}

\author{
Luiza Kajumovna Karimova \\ Associate Professor, Institute Of International Relations, History And Oriental Studies \\ Kazan (Volga Region) Federal University, Kazan, Russia \\ lu_ka_s@rambler.ru \\ Anna Andreevna Kirpichnikova \\ Assistant Professor, Institute Of International Relations, History And Oriental Studies \\ Kazan (Volga Region) Federal University, Kazan, Russia
}

\begin{abstract}
Under the conditions of informatization in different spheres of society living, including educational sphere, investigation universities' experience in applying of concrete information analysis systems (IAS), their structure and capabilities becomes more and more popular. The article using information analysis system of Kazan Federal University (KFU) "Electronic University" deals with advantages of usage information analysis systems in the sphere of historical education implemented in the Institute of International Relations, History and Oriental Studies, problems connected with such systems and ways of overcoming these problems. Among advantages there are reduction of time spent on the preparation of documents related to the educational process, the reduction of the hard-copy paperwork, strengthening and facilitating the communication between teachers and students, improving the competitive ability of educational services, standardization of processes in the sphere of educational activities, etc. Among problems there are voluminosity and difficult control system of IAS, duplication of training materials in the IAS and traditional document management, technical issues, lack of proficiency in the skills of employees working in the IAS, etc. And it is possible to solve these problems by creating hierarchical system of subordination of the moderators, introducing in IAS the special functions for monitoring and correction of technical problems, introducing regular system of training of employees working in the IAS
\end{abstract}

Keywords: information analysis system, historical education, university's learning activity, corporate information environment, Knowledge Management

\section{INTRODUCTION}

Leading universities pay particular attention to automation and informatization of the main processes of their activity to solve problems modern universities face more efficiently. The analysis of different variants of IAS in universities' learning activity is very important from theoretical and practical points of view all the more at the modern stage of implementation of information systems in Russian universities. One of the most high efficient, corresponding to Russian and world trends of university management systems is information analysis system of Kazan Federal University "Electronic University".

Among main advantages of application of its modules in the sphere of historical education, implemented in Kazan Federal University there are: saving of time and money, and so increasing of efficiency of educational process, quality of educational services and their competitive ability in Russian and international markets. At the same time there are some problems which decrease efficiency of the application of information analysis system: complex and volume structure; necessity to double training materials in the IAS and traditional document management, technical issues, lack of proficiency in the skills of employees working in the IAS, etc. 
Results of the research can be taken into consideration when preparing scientific works, elaborating training aids, connected with automation of different directions of universities' activity, application of information technologies in educational activities, etc.

\section{METHODS}

During writing this work, how general scientific methods (analysis, abstracting, induction, modeling, etc.) so special methods (participant observation, structural and system methods) were used.

\section{RESULTS AND DISCUSIONS}

The use of informationsystems as means of optimization of main directions of Russian universities' activity started not long ago and now it gains momentum actively. Such trend is more typical for large universities as KFU, which have thousands employees and students, branches, basis of practice, preproduction, etc.

There are no many researches devoted to the application of informationsystems in the management system of modern Russian universities, especially in the sphere of historical education. Among Russian writers, which are interested in this problem, thereis E.N. Babina, dealing questions of dataware of university's management system [1], D.A. Belyaeva, concerning application of information systems of management economical processes at the university [2], D.A. Ivanchenko, investigating optimization of creating university's informational management system [3], V.V. Krukov, searching information technologies in the university's management [4], etc. Foreign scientists paid their attention to these problems too [5], but generally their works on this subject are common, rather theoretical. At the same time nowadays it is necessary to analyze efficiency of application of concrete IAS in different directions of universities' activity.

At the present stage, such solutions are actual among Russian universities: solutions based on ERPsystem ("1C: University", "Galaxy-university", etc.) and solutions elaborated especially for universities ("Axiom", «Tandem University», «Universys WS», «Modeus-university», «University», etc.). Moreuniversitiesstudiedmarketofsoftwaresolutions preferred automation in concrete directions (management of educational process, management of financial processes, and organizationof enrollment campaign) to complex automation.

In the sphere of educational activity, including historical education, Kazan Federal University elaborates and inculcates informational analysis system "Electronic University". Oneof the most important advantages of IAS is that it is oriented on complex automation of all university's business processes (first of all educational, scientific and administrative activity) and informational and telecommunication infrastructure consisted of information analysis system in other words program on collecting, saving and paper handing and another information, applied to university's activity and university's website, including sites of all university's departments.

"ElectronicUniversity" consists of five main program relative and dynamically developed modules: automation of management of educational process, dataware of working process, educational and scientific activity of user, automation of management of financial and business processes to ensure the university of life,providing relevant information about the University, providing web services for staff and students of Kazan Federal University, the implementation of the integration of the modules of information analysis system, support the process of ensuring the smooth operation of structural units of computer equipment and software.

The use of tools of the first two modules in the sphere of historical education implemented in Institute of International Relations, History and Oriental Studiesallows to reduce hard-copy paperwork inside organization, to reduce time that is necessary to bring managers' orders to the stuff, to make an accounting accordance and communication between teachers and students easier. Thus, expenses decrease (paper, printer cartridges, stationary costs, etc.); at the expense of saving time efficiency and labour productivity increase, communication becomes better (stuff and students, being in different university's building and outside have access to IAS and can work there). 
University's website of distance learning works to increase competitive ability of educational services in the sphere of historical education (http://edu.kpfu.ru). Moreover, there is the site for creation of electronic and educational sources and their access in educational process (http://do.kpfu.ru). Next fact can prove the efficiency of these sites: there are 97 electronic and educational programs used by professors in teaching process and 238 programs are elaborated now in different departments of the Institute of International Relations, History and Oriental Studies.

Mentioned sites integrated with system "Electronic University" within the framework of common authorization. System users can not only elaborate distance educational courses but also use integral system of webinars, video lections and video conference communication. All this allows to increase quality of educational services and their being in demands in market of historical education.

Furthermore, information analysis system's module "For teacher" allows to create your timetable from timetables created by deanery in the module "For student", to put in the results of the monitoring of students knowledge, to mark students' lectures attendance, to fill in educational programs of the subject taught by users, to organize distance learning with the help of "Virtual auditorium". Mentioned functions allow teachers to reduce the time and official circumlocution, to ensure managers, Department of education, resource teachers quick access to the information about teacher, to form educational materials and reports in time.

Efficiency of application of IAS of Kazan Federal University in the sphere of historical education becomes more stronger owing to unification of the processes directed to: organization of learning activity ( access to training materials and electronic educational sources, electronic catalogues and libraries, communication with the teacher online and offline), control educational process (creating timetable, nomenclature of files and registration of lectures attendance and marks, statistics and reports, etc.), control learning content (tools for creating electronic reference books and relative texts and multimedia materials, etc.).

One more condition of the successful use of information analysis system in the sphere of historical education is corporative information environment formed at the university and had such features as fullness of facts (there is all necessary information about main directions of activity, relativeness of corporative information), authenticity (provides organizational solutions for the implementation of data entry, namely, the existence of different degrees of access to authorized users, a large number of users, etc.), actuality (provides organizational solutions to ensure the timely entry of data), safe and control under access to information(the presence in IAS registration and management of access rights to all information resources of the University).

At the same time there are some problems decreasing efficiency of the application of IAS of Kazan Federal University in the sphere of historical education:

1. Try to automate all directions of university's activity in one information analysis system makes this system very volume and difficult for control. It is possible to solve the problem of awkwardness of the system, especially when more than ten thousand users work in it and when every day new directions of university's activity are automatized only by increasing the number of moderators on different modules and parts of system. They will follow the normal functioning of the IAS in their respective field, the timeliness, authorship, and (as far as possible) the reliability of the information entered, carry moderating function. This effective system is hierarchical subordination from larger to smaller sections rather than the presence of many not interconnected moderators.

2. There is problem of duplication of different reports, steering documents, educational documents, etc. in the IAS and traditional document management that increases time spending and effects on modern creating reports by employees in IAS.

3. Technical problems in IAS of KFU. Sometimes there is necessarily toenter the information into the system for a long time, and even several times (in different parts of IAS in case of technical deficiency of the system), that can which, of course, also affects the cost of temporary staff and their motivation to use it. There are some ways to solve this problem? And one of them is to add to the 
information analysis system's function "Request for improvement" and regular round tables with participation of system developers, decision-makers, moderators and ordinary users.

4. The problem of insufficient training of the staff in the field of work in the IAS, what is solved by regular training users and providing them with personal cabinet of access to the instructions, guidelines and regulations related to the work in the various modules of IAS. It would be advisable to carry out professional training system upon employment (for working at re-certification), along with lectures on safety, for students in the first course in introductory classes.

\section{CONCLUSIONS}

IAS of KFU "Electronic University" is one of the most effective Russian information systems focused on complex automation of the main activities of the Kazan Federal University. Using its functionality in the field of historicaleducation, realized in high school, can significantly reduce hard-copy paperwork in the organization, the time required for teachers to prepare teaching materials, increase efficiency and employee productivity, facilitate communication of teachers and students, and as a result of all this, to improve the quality of educational services and their market demand of historical education.

At the same time there are a number of problems decreasing the effectiveness of the application of IAS of KFU in historical education, and it is necessary to solve them: the volume and complex structure of the system; the need to duplicate statements, work programs, training documentation, etc. in IAS and the traditional "paper" document circulation; technical defects; lack of training of the personnel in the field of work in the IAS.

\section{ACKNOWLEDGEMENTS}

The work is performed according to the Russian Government Program of Competitive Growth of Kazan Federal University.

\section{REFERENCES}

Babin E.N. Information support of the university management: the benefits of process-modular approach / E.N.Babin // University Management: Practice and Analysis. - 2011. - № 6. - PP.15-22.

Belyaev D.A. The use of management information systems as an essential element of strategic management of economic processes in the university / D.A.Belyaev // University Management: Practice and Analysis. - 2004. - №5-6. - PP.179-183.

Ivanchenko D.A.: Construction of information infrastructure of the university using the SaaS model // Higher education in Russia - 2010 - №10. - PP. 11-17.

KryukovV.V. Information technology in university management / V.V.Kryukov, K. Shahgeldyan // University Management: Practice and Analysis. - 2005. - № 2. - PP.85-94.

Alavi, M., Leidner D.E. 2001. Review: Knowledge Management and Knowledge Management Systems: Conceptual Foundations and Research Issues. MIS Quarterly, 25 (1).107-136; GalandereZile, I. 2002.Application of knowledge management elements for quality management systems. In 11th International Conference on Information Systems Development, Riga, eds. J. Stirna and K. Steins, 15-25. Riga: Riga Technical University; Galandere-Zile, I. 2004. Applicability of erp systems for knowledge management in the context of quality management.In The 16th International Conference on Advanced Information Systems Engineering, Riga, eds. A. Persson and J. Stirna, 27689. Riga: Springer; KettunenJuha. 2009. Management Information System in Higher Education. Encyclopedia of Information Communication Technology.542-547; Mellor Robert. 2011. Knowledge Management and Information Systems: Strategies for Growing Organizations. 208; Moreno Jr. Valter, CavazotteFlavia. 2015. Using Information Systems to Leverage Knowledge Management Processes: The Role of Work Context, Job Characteristics and Task-Technology Fit. Procedia Computer Science. Volume 55.360-369, etc. 